\title{
Genetic interaction between the non-homologous end-joining factors during B and T lymphocyte development: In vivo mouse models
}

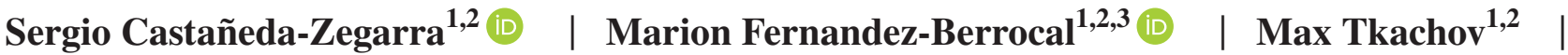 \\ Rouan Yao $^{1,2}$ | Nikki Lyn Esnardo Upfold ${ }^{1,2}$ (D) | Valentyn Oksenych ${ }^{1,2,4,5}$ (iD
}

${ }^{1}$ Department of Clinical and Molecular Medicine (IKOM), Norwegian University of Science and Technology, Trondheim, Norway

${ }^{2}$ St. Olavs Hospital, Clinic of Medicine, Trondheim University Hospital, Trondheim, Norway

${ }^{3}$ Behavioural Neurobiology MS Program, Theodor-Boveri-Institute, Biocenter, University of Würzburg, Würzburg, Germany

${ }^{4}$ Department of Biosciences and Nutrition (BioNut), Karolinska Institutet, Huddinge, Sweden

${ }^{5}$ Department of Clinical Medicine, Faculty of Health Sciences, UiT-The Arctic

University of Norway, Troms $\emptyset$, Norway

\section{Correspondence}

Valentyn Oksenych, Department of Clinical and Molecular Medicine (IKOM), Norwegian University of Science and Technology, Trondheim 7491, Norway. Email: valentyn.oksenych@uit.no

\section{Funding information}

Helse Midt-Norge, Grant/Award Number: \#38881; Outstanding Academic Fellow 2.0, NTNU, Grant/Award Number: 2017-2021; Kreftforeningen, Grant/Award Number: 182355

\section{$1 \mid$ INTRODUCTION}

DNA double-strand breaks (DSBs) are generated both extrinsically, for example, by chemotherapeutic agents, and physiologically, for example, during $\mathrm{V}(\mathrm{D}) \mathrm{J}$ recombination in

\begin{abstract}
Non-homologous end joining (NHEJ) is the main DNA repair mechanism for the repair of double-strand breaks (DSBs) throughout the course of the cell cycle. DSBs are generated in developing $\mathrm{B}$ and $\mathrm{T}$ lymphocytes during $\mathrm{V}(\mathrm{D}) \mathrm{J}$ recombination to increase the repertoire of $\mathrm{B}$ and $\mathrm{T}$ cell receptors. DSBs are also generated during the class switch recombination (CSR) process in mature B lymphocytes, providing distinct effector functions of antibody heavy chain constant regions. Thus, NHEJ is important for both V(D)J recombination and CSR. NHEJ comprises core Ku70 and Ku80 subunits that form the Ku heterodimer, which binds DSBs and promotes the recruitment of accessory factors (e.g., DNA-PKcs, Artemis, PAXX, MRI) and downstream core factors (XLF, Lig4 and XRCC4). In recent decades, new NHEJ proteins have been reported, increasing complexity of this molecular pathway. Numerous in vivo mouse models have been generated and characterized to identify the interplay of NHEJ factors and their role in development of adaptive immune system. This review summarizes the currently available mouse models lacking one or several NHEJ factors, with a particular focus on early B cell development. We also underline genetic interactions and redundancy in the NHEJ pathway in mice.
\end{abstract}

developing B and T lymphocytes, and class switch recombination (CSR) in activated mature B cells. ${ }^{1,2}$

The DNA damage response (DDR) pathway is initiated upon the induction of DSBs. Ataxia telangiectasia mutated (ATM) is a DDR regulator protein kinase that phosphorylates

This is an open access article under the terms of the Creative Commons Attribution License, which permits use, distribution and reproduction in any medium, provided the original 
multiple substrates in response to the DSBs, including histone $\mathrm{H} 2 \mathrm{AX}$, modulator of DNA damage checkpoint 1 (MDC1) and p53-binding protein 1 (53BP1). Phosphorylated H2AX facilitates the recruitment of $\mathrm{MDC} 1$, following the activation of Really Interesting New Gene (RING) Finger Protein 8 (RNF8) and RNF168, which are ubiquitin ligases. Phosphorylated and ubiquitinated $\mathrm{H} 2 \mathrm{AX}$ facilitates recruitment of 53BP1, which in turn mediates recruitment of RIF1 and interacts with Rev7. The Shieldin complex also promotes DNA repair. ${ }^{1,3}$ Accumulation of DSBs results in ATM-dependent activation of checkpoint kinases 1 and 2 (CHK1 and CHK2), which arrests the cell cycle, followed by phosphorylation and stabilization of p53, which triggers apoptosis. 4

In mammalian cells, the non-homologous end-joining (NHEJ) pathway repairs the majority of DSBs. ${ }^{5-7}$ There are evolutionary conserved NHEJ factors referred to as 'core' factors, as well as accessory factors that may be dispensable for DNA repair in wild-type cells. $\mathrm{Ku} 70, \mathrm{Ku} 80, \mathrm{X}$-ray repair cross-complementing protein 4 (XRCC4), DNA ligase 4 (Lig4) and XRCC4-like factor (XLF) are core factors, ${ }^{8-12}$ while DNA-dependent protein kinase catalytic subunit (DNA-PKcs), ${ }^{13-16}$ Artemis nuclease, ${ }^{17}$ paralogue of XRCC4 and XLF (PAXX), ${ }^{18-21}$ and modulator of retroviral infection $(\mathrm{MRI})^{22,23}$ are usually considered accessory factors.

During the last years, several models have been proposed to explain how the two free DNA ends are brought back together through synapsis. In particular, Loparo's group ${ }^{7}$ suggested a two-stage model of NHEJ synaptic complex assembly, where DNA ends are initially tied in a long-range complex, followed by transition into a short-range complex. In this model, Ku70, Ku80 and DNA-PKcs (DNA-PK) first participate in the formation of the initial long-range complex, where DNA ends are held sufficiently distant. Then, the short-range complex is formed by DNA-PK, XLF, Lig4 and XRCC4. PAXX and MRI have not been implicated in this model because their functions have not been identified. ${ }^{7}$ Another model proposed by Lieber's group $^{24}$ suggests that there are two major structural complexes formed during the NHEJ synapsis. Ku70, Ku80, XRCC4 and Lig4 form the flexible synaptic (FS) complex, where XRCC4 and Lig4 bind to each DSB through interaction of Lig4 with $\mathrm{Ku}$ heterodimer. Subsequently, DSBs are brought together through interaction of XRCC4, giving rise to two Ku-XRCC4-Lig4DNA complexes. XLF and PAXX both promote transition from FS to the second synaptic complex, called close synapsis (CS), although XLF stabilizes CS to a greater extent. XLF stimulates and impacts the general synapsis efficiency mediated by $\mathrm{Ku}$ XRCC4-Lig4. It is suggested that DNA-PKcs is not required for the formation of either FS or CS. This latter model explains the evolutionarily central synaptic role of the core NHEJ factors, $\mathrm{Ku} 70, \mathrm{Ku} 80, \mathrm{XRCC} 4, \mathrm{Lig} 4$ and XLF. ${ }^{24}$

For practical purposes, NHEJ can be divided into three major stages: DSB recognition, stabilization-processing and end ligation. ${ }^{25}$ Initially, DSBs are recognized by the heterodimer $\mathrm{Ku}$, which is formed by $\mathrm{Ku} 70$ and $\mathrm{Ku} 80 . \mathrm{Ku}$ assists the recruitment of DNA-PKcs, ${ }^{13-16}$ forming the DNA-PK holoenzyme. Subsequently, Artemis nuclease, ${ }^{17}$ $\mathrm{PAXX}^{18-21}$ and $\mathrm{MRI}^{22,23}$ are recruited to the DSB sites. Finally, XLF, XRCC4 and Lig4 mediate the Ku-dependent DNA end ligation. ${ }^{1}$

During the early stages of B and T cell development, NHEJ is required for the $\mathrm{V}(\mathrm{D}) \mathrm{J}$ recombination assembling immunoglobulin (Ig) and $T$ cell receptor (TCR) genes using $V, D$ and $J$ gene segments. Both Ig and TCR provide antigen-binding specificity required for an efficient immune response. The proteins encoded by the recombination activating genes 1 and 2 (RAG1,2) form an endonuclease (RAG) that recognizes recombination signal sequences (RSSs) flanking the $V, D$ and $J$ gene segments. $^{26}$

Class switch recombination takes place in mature B cells, when constant regions of immunoglobulins switch from IgM to IgG, Ig A or IgE. Immunoglobulins, or antibodies, play a crucial role in immune response through their effector functions. CSR is initiated by activation-induced cytidine deaminase (AID). In repetitive switch regions of Igh gene, AID deaminates deoxycytidine resulting in deoxyuracil $(\mathrm{dC}>\mathrm{dU})$. The dUs are excised by the uracil DNA N-glycosylase (UNG) enzyme, leaving an abasic (apyrimidinic/apurinic [AP]) site. ${ }^{27}$ The AP sites are cut by AP endonuclease (APE) 1 or APE2, producing DNA single-strand breaks (SSB). Two SSBs on the opposite DNA strands form DSBs, initiating the CSR. ${ }^{27}$ The joining of DSBs during the CSR is performed both by the classical NHEJ (C-NHEJ) and alternative end joining (AEJ). ${ }^{28}$ Strikingly, the A-EJ can maintain up to $50 \%$ of CSR activity in the absence of core C-NHEJ factors, such as Ku70, XRCC4, Lig4 and XLF. ${ }^{1}$

Other proteins, such as members of the DNA polymerase $\mathrm{X}$ family and terminal deoxynucleotidyl transferase enzyme (TdT), can also be involved in C-NHEJ within B cells. ${ }^{29,30}$ For example, DNA polymerase proteins Pol $\lambda$ and Pol $\mu$ promote DNA end joining through the processing of DSBs, while TdT increases the antibody and TCR repertoire by adding non-template nucleotides prior to ligation of DNA ends during V(D)J recombination. ${ }^{29,30}$ Proteins such as nipped-Blike protein (NIPBL) and breast cancer 1 (BRCA1) have also been shown to play a role in NHEJ. ${ }^{31,32}$

\section{2 | NON-HOMOLOGOUS END- JOINING-DEFICIENT MICE}

Before transgenic mice became popular, an inbred strain of immunodeficient mice with severe combined immunodeficiency (SCID) was identified. ${ }^{33}$ First characterized by Bosma et $a l,{ }^{33}$ SCID mice carry a recessive mutation in the Dnapkcs gene, which results in impaired $\mathrm{V}(\mathrm{D}) \mathrm{J}$ recombination and a subsequent lack of mature $\mathrm{B}$ and $\mathrm{T}$ lymphocytes in 
homozygous mice. Later, transgenic mouse models deficient for Dna-pkcs gene were generated by several groups. ${ }^{13-16}$ DNA-PKcs-deficient mice (Dna-pkcs $\left.{ }^{-/}\right)$are live-born and possess a SCID phenotype due to inefficient coding-end (CE) joining during the V(D)J recombination ${ }^{13}$ (Figure 1). Artemis $^{-/-}$mice have also been observed to exhibit a SCID phenotype due to lack of CE joining. ${ }^{17}$ Thus, both DNA-PKcs and Artemis are required for processing of RAG-mediated hairpin-sealed DNA ends (CEs) during V(D)J recombination, although repair of blunt signal ends (SEs) remains efficient in mice lacking Artemis ${ }^{17}$ or DNA-PKcs. ${ }^{13-15}$ Inactivation of $K u 70^{11}$ or $K u 80^{10}$ in mice results in reduced body weight and a SCID phenotype. Lack of B and T lymphocytes in $K u 70^{-/-}$ and $\mathrm{Ku} 8 \mathrm{O}^{-/-}$mice is explained by inefficient joining of both RAG-induced blunt SEs and hairpin-sealed CEs. ${ }^{10,11}$

In contrast, inactivation of $\mathrm{Lig} 4^{8}$ or $\mathrm{Xrcc}^{9}$ results in embryonic lethality in mice, presenting challenges for in vivo studies. However, cell studies show that inactivation of Lig4 or Xrcc4 led to inefficient joining of both SEs and CEs, resembling Ku-deficient phenotypes in mice. This suggests that such in vivo models would yield an immunodeficient animal due to ablated V(D)J recombination and lack of B and T cells, if one could be generated. ${ }^{8,9}$

Several single-deficient mouse models initially suggested that XLF, PAXX and MRI are dispensable for the V(D)J recombination. Particularly, mice lacking XLF/Cernunnos ${ }^{34,35}$ possess both mature $\mathrm{B}$ and $\mathrm{T}$ cells, despite being characterized by modest lymphocytopenia, and reduced repertoires of B cell receptors and TCRs. ${ }^{34,35} \mathrm{Xlf}^{-/-}$lymphocytes support efficient $\mathrm{V}(\mathrm{D}) \mathrm{J}$ recombination in vitro, including both SE and CE repair. ${ }^{34,35}$ Mice lacking either PAXX ${ }^{18,19,21,36}$ or $\mathrm{MRI}^{22,23}$ possess normal counts of mature $\mathrm{B}$ and $\mathrm{T}$ cells, efficiently supporting both SE and CE repair during the V(D)J recombination. However, more complex mouse models have revealed that XLF, PAXX and MRI are required for V(D)J recombination, although their functions are compensated by each other and additional proteins due to the extensive genetic interaction inside the NHEJ pathway, as well as interaction between the NHEJ and DDR pathways. ${ }^{1,37}$

$\mathrm{Xlf}^{-1-34,35}$ and Dna-pkcs${ }^{-/ 13}$ mice show notable radiosensitivity, but result in viable mice. However, double-deficient $\mathrm{Xlf}^{-1-}$ Dna-pkcs ${ }^{-/-}$mice are characterized by perinatal lethality and increased genomic instability, due to nearly no NHEJ ${ }^{38}$ While lymphocytes lacking either XLF or DNA-PKcs are capable of repairing RAG-induced blunt SEs, $\mathrm{Xlf}^{--}{ }^{-} \mathrm{Dna}$ $\mathrm{pkcs}^{-/-}$cells are unable to join SEs. ${ }^{38}$ Embryonic lethality of $\mathrm{Xlf}^{-1-}$ Dna-pkcs ${ }^{-/}$mice is p53- and Ku-dependent, and triple-de-

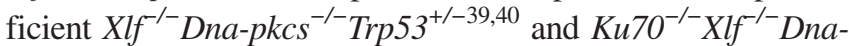
$\mathrm{pkss}^{-/-40}$ mice are live-born, although they possess reduced body weight comparable to one of $K u 70^{-/-}$mice..$^{39,40}$

$\mathrm{Xlf}^{-1-}$ Dna- $\mathrm{kcs}^{-/-}$was the first mouse model that highlighted genetic interaction between Xlf and accessory

\begin{tabular}{|c|c|c|c|c|c|c|c|c|c|}
\hline Lig4 & $\begin{array}{l}\text { SCID } \\
\text { Size } \downarrow\end{array}$ & $\begin{array}{c}\text { SCID } \\
\text { Size } \downarrow \checkmark\end{array}$ & & & & Lethal $x$ & & & $\begin{array}{l}\text { Lethal } \\
\text { CNS cell death }\end{array}$ \\
\hline Xrcc4 & & & & & & & & $\begin{array}{c}\text { Lethal } \\
\text { CNS cell death }\end{array}$ & \\
\hline Mri & & & Lethal & & Lethal & Nearly wt $X$ & Nearly wt & & \\
\hline Paxx & & $\begin{array}{c}\text { SCID } \\
\text { Size } \downarrow \times\end{array}$ & ${ }^{\text {SCID }} \times$ & & $\begin{array}{l}\text { Lethal } \\
\text { CNS cell death }\end{array}$ & Normal & $\stackrel{\text { Nearly wt }}{X}$ & & ${ }^{\text {Lethal }} \times$ \\
\hline$X I f$ & $\begin{array}{l}\text { SCID } \\
\text { Size } \downarrow \times\end{array}$ & $\begin{array}{l}\text { SCID } \\
\text { Size } \downarrow \times\end{array}$ & Lethal $\checkmark$ & ${ }^{\text {SCID }} \times$ & $\begin{array}{l}\text { Mild ID, } \\
\text { CSR } \downarrow\end{array}$ & $\begin{array}{l}\text { Lethal } \\
\text { CNS cell death }\end{array}$ & Lethal & & \\
\hline Artemis & & & & SCID & ${ }^{S C I D} \times$ & & & & \\
\hline Dna-pkcs & $\begin{array}{l}\text { SCID } \\
\text { Size } \downarrow \times\end{array}$ & $\begin{array}{l}\text { SCID } \\
\text { Size } \downarrow \times\end{array}$ & SCID & & Lethal & ${ }^{S C I D} \times$ & Lethal & & \\
\hline Ku80 & & $\begin{array}{c}\text { SCID, CSR } \downarrow \\
\text { Size } \downarrow \\
\text { CNS cell death }\end{array}$ & $\begin{array}{l}\text { SCID } \\
\text { Size } \downarrow \times\end{array}$ & & $\begin{array}{l}\text { SCID } \\
\text { Size } \downarrow \times\end{array}$ & $\begin{array}{l}\text { SCID } \\
\text { Size } \downarrow \times\end{array}$ & & & $\begin{array}{l}\text { SCID } \\
\text { Size } \downarrow \checkmark\end{array}$ \\
\hline Ku70 & $\begin{array}{c}\text { SCID, CSR } \downarrow \\
\text { Size } \downarrow \\
\text { CNS cell death }\end{array}$ & & $\begin{array}{l}\text { SCID } \\
\text { Size } \downarrow \times\end{array}$ & & $\begin{array}{c}\text { SCID } \\
\text { Size } \downarrow \times\end{array}$ & & & & $\begin{array}{l}\text { SCID } \\
\text { Size } \downarrow \checkmark\end{array}$ \\
\hline Genes & Ku70 & Ки80 & Dna-pkcs & Artemis & $X l f$ & Paxx & Mri & $\operatorname{xrcc4}$ & Lig4 \\
\hline
\end{tabular}

Single deficiency

$\checkmark$ Genetic interaction

$\times$ No genetic interaction

F I G U RE 1 Genetic interactions between the NHEJ factors in mice. The phenotypes of mice are indicated. Genetic interactions are marked as $\checkmark$. The lack of interaction is marked as $\times$ 
NHEJ factors in vivo (Figure 1). Mice lacking both XLF and Artemis are live-born, are fertile and have a SCID phenotype resembling single-deficient Artemis ${ }^{-1-}$ mice, ${ }^{38}$ suggesting no genetic interaction between $X l f$ and Artemis in vivo. Later, genetic interaction between $X l f$ and Paxx was characterized in vivo independently by four research groups. ${ }^{18,19,36,39}$ Mice lacking both XLF and PAXX possess late embryonic lethality, increased genomic instability and immunodeficiency; and $X l f^{-/-} \mathrm{Paxx}^{-/-}$lymphocytes are unable to sustain repair of both SEs and CEs generated during V(D)J recombination. ${ }^{18,19,36,41}$ The embryonic lethality of $X l f^{-/-} \mathrm{Paxx}^{-/-}$mice is p53-dependent, and both

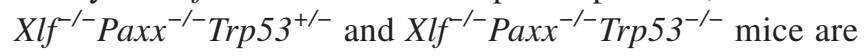
live-born, but possess significant weight reduction and a leaky SCID phenotype with nearly no mature B and T lymphocytes. ${ }^{39,42}$

Furthermore, $\mathrm{Xlf}^{-/-} \mathrm{Mri}^{-/-}$double knockout mice are embryonic lethal, ${ }^{23}$ but can be rescued by inactivation of one or two alleles of Trp53. ${ }^{42}$ Mice lacking both XLF and MRI are characterized by leaky SCID with nearly no mature B and $\mathrm{T}$ lymphocytes due to the $\mathrm{V}(\mathrm{D}) \mathrm{J}$ recombination defect. ${ }^{23}$ In particular, the lymphocytes lacking both XLF and MRI are unable to efficiently ligate both RAG-mediated SEs and CEs in vitro. ${ }^{23}$ Both the double-deficient mouse model lacking XLF and PAXX and the model lacking XLF and MRI are characterized by leaky SCID with low but detectable levels of mature B and T lymphocytes. ${ }^{42}$ This phenotype is likely possible due to residual NHEJ activity in developing $\mathrm{Xlf}^{-/-} \mathrm{Paxx}^{-/-}$and $\mathrm{Xlf}^{-/-} \mathrm{Mri}^{-/-}$lymphocytes in vivo. ${ }^{39,42}$

Thus, there is evidence that $X l f$ genetically interacts with Dna-pkcs, ${ }^{38-40}$ Paxx $^{18,19,36,39,42}$ and Mri. ${ }^{23,42}$ Further transgenic mouse studies address whether Dna-pkcs genetically interacts with Paxx and Mri, and whether Paxx genetically interacts with Mri. Dna-pkcs ${ }^{-/-} \mathrm{Paxx}^{-/-}$mice are live-born, fertile and indistinguishable from Dna- $\mathrm{kcs}^{-/-}$littermates. ${ }^{39}$ Furthermore, $\mathrm{Mri}^{-/-} \mathrm{Paxx}^{-/-}$mice possess nearly no detectable phenotype, similar to single-deficient $\mathrm{Mri}^{-/-}$and $\mathrm{Paxx}^{-/-}$mice. ${ }^{42}$ In contrast, Dna- $\mathrm{kcs}^{-/-} \mathrm{Mri}^{-/-}$mice are embryonic lethal. ${ }^{42}$ Therefore, there is no genetic interaction between Dna-pkcs and Paxx, or Mri and Paxx; however, Dnapkcs and Mri interact genetically (Figure 1).

Inactivation of $\mathrm{Ku}$, Trp53 or Atm rescues embryonic lethality of $\mathrm{Lig}^{-/-}$mice. In particular, $\mathrm{Ku} 80^{-/-} \mathrm{Lig}^{-/-43}$ and $K u 70^{-1-} \mathrm{Lig}^{-/-44}$ mice are not distinguishable from Ku-deficient mice, possessing reduced body weight, increased levels of genomic instability and a SCID phenotype. Furthermore, Lig $4^{-/-} \operatorname{Trp} 53^{+/-}$and $\operatorname{Lig} 4^{-/-} \operatorname{Trp} 53^{-/-}$mice, although live-born, possess reduced body weight, increased levels of genomic instability and SCID due to inability to repair SEs and CEs during V(D)J recombination. ${ }^{45}$ Moreover, Lig $4^{-/-}$Trp $53^{+/-}$mice present a more severe phenotype than Lig $4^{-1-}$ Trp $53^{-/-}$littermates, likely due to an incomplete block of DNA damage-induced apoptosis in the presence of one Trp53 allele. ${ }^{45}$ In addition, inactivation of one or two alleles of Atm rescued lethality in Lig4-deficient mice. ${ }^{46}$ Both $\mathrm{Lig}^{-/-} \mathrm{Atm}^{+/-}$and $\mathrm{Lig}^{-/-} \mathrm{Atm}^{-/-}$mice displayed impairment in lymphocytic development, growth retardation and short lifespan (up to 2 days postnatally). ${ }^{46}$ Further, inactivation of one or two alleles of Trp53 rescues embryonic lethality of $\mathrm{Xrcc}^{-/-}$mice. ${ }^{47}$ The $\mathrm{Xrcc} 4^{-/-} \operatorname{Trp} 53^{+/-}$mice possess a more severe phenotype when compared to the $X r c c 4^{-/-} \operatorname{Tr} p 53^{-/-}$ littermates, although both models are characterized by reduced body weight, increased genomic instability and SCID due to inability to repair RAG-induced DSBs in developing B and T cells. ${ }^{47}$

Several complex mouse models have also revealed a lack of genetic interaction between different pairs of NHEJ genes (Figure 1). In particular, mice lacking Ku80 and either XLF $\left(K u 80^{-/-} \mathrm{Xlf}^{-/-}\right)$, PAXX $\left(\mathrm{Ku} 80^{-/-} \mathrm{Paxx}^{-/-}\right)^{19}$ or DNAPKcs $\left(K u 80^{-/-} \text {Dna- } \mathrm{pks}^{-/-}\right)^{48}$ are indistinguishable from $\mathrm{Ku} 80^{-/-}$mice, whereas $\mathrm{Ku} 70^{-/-} \mathrm{Xlf}^{-/-}$and $\mathrm{Ku} 70^{-/-} \mathrm{Dna}$ $\mathrm{pcs}^{-/-}$mice are indistinguishable from $\mathrm{Ku} 70^{-/-}$littermates. ${ }^{40}$ Finally, embryonic lethality of $\mathrm{Lig}^{-/-}$mice is not rescued by the inactivation of $\mathrm{Paxx}^{-/-}\left(\mathrm{Lig}^{-/-} \mathrm{Paxx}^{-/-}\right)^{19}$ (Figure 1).

\section{1 | Class switch recombination}

Class switch recombination occurs in mature B cells following the efficient $\mathrm{V}(\mathrm{D}) \mathrm{J}$ recombination in vivo. However, several experimental models allow for the bypass of V(D) $\mathrm{J}$ recombination to determine the impact of specific factors on CSR, even though these factors are required for earlier stages of B cell development (e.g., Artemis, DNA-PKcs). Knocking-in pre-assembled heavy and light chains of the immunoglobulin gene ('HL') allows for the development of mature B cells in mice that otherwise lack the capacity for V(D)J recombination. ${ }^{49}$ For example, lack of Artemis or DNA-PKcs ${ }^{49}$ moderately affects the CSR in mature B cells. Additionally, it was found that CSR levels were reduced two- to threefold in cells lacking XLF, ${ }^{34,35} \mathrm{Ku} 70,{ }^{44} \mathrm{Ku} 80,{ }^{44}$ Lig4 ${ }^{28}$ or XRCC4. ${ }^{28}$ PAXX seems to be dispensable for CSR in wild-type cells, ${ }^{18,19,21,36,50}$ while inactivation of Mri results in modest CSR defects. ${ }^{22,23,42}$

DNA-PKcs and XLF are functionally redundant in $\mathrm{CSR}^{38} \mathrm{PAXX}$ is also functionally redundant with XLF $\left(X^{-/-} \mathrm{Paxx}^{-/-}\right.$cell lines $){ }^{51}$ but not with MRI $\left(\mathrm{Mri}^{-/-} \mathrm{Paxx}^{-/-}\right.$mice $){ }^{42}$

\section{2 | Genetic interaction between NHEJ and DDR factors}

DNA damage response factors genetically interact with NHEJ components. Atm is synthetically lethal with $K u 70$ 
$\left(\mathrm{Atm}^{-/-} \mathrm{Ku}^{-1-}\right), \quad \mathrm{Ku} 80 \quad\left(\mathrm{Atm}^{-/-} \mathrm{Ku} 8 \mathrm{O}^{-/-}\right)$and Dna-pkcs $\left(\mathrm{Atm}^{-/-} \text {Dna-pkcs }{ }^{-/-}\right)^{46}$ (Figure 2). Combined inactivation of Atm and Dna-pkcs in cells results in more severe CSR defects than in single-deficient controls. ${ }^{52}$ Moreover, $\mathrm{Atm}^{-/}$Dna$\mathrm{pkcs}^{-1-}$ pro-B cells lack repair of both SEs and CEs during the attempted V(D)J recombination. ${ }^{53}$

Furthermore, Xlf genetically interacts with Atm, 53bpl, $H 2 a x$ and $M d c 1 . .^{37,54-56}$ In particular, mice lacking XLF and ATM $\left(\mathrm{Xlf}^{-/-} \mathrm{Atm}^{-/-}\right)$are live-born, possess reduced body weight and CSR, increased genomic instability and lack of $\mathrm{V}(\mathrm{D}) \mathrm{J}$ recombination in developing $\mathrm{B}$ and $\mathrm{T}$ cells, resulting in severe lymphocytopenia (Figure 2). ${ }^{1,54} \mathrm{Xlf}^{-/} 53 \mathrm{bp1^{-/- }}$ mice are live-born, possess reduced body weight, increased genomic instability and reduced $\mathrm{B}$ and $\mathrm{T}$ cell count due to the block in $\mathrm{V}(\mathrm{D}) \mathrm{J}$ recombination in developing lymphocytes (Figure 2) ${ }^{55,56}$ Synthetic lethality does arise with Xlfand H2ax as well as $X l f$ and $M d c l$ in mice, and double-deficient pre-B cells, $\mathrm{Xlf}^{-/-} \mathrm{H} 2 \mathrm{ax}^{-/-}$and $\mathrm{Xlf}^{-/-} \mathrm{Mdcl} \mathrm{I}^{-/-}$, possess reduced efficiency of V(D)J recombination. ${ }^{37,54}$ Finally, Atm does not interact genetically with Paxx and $\mathrm{Mri}$. $\mathrm{Atm}^{-/-} \mathrm{Paxx}^{-/-}$cells possess DNA repair levels similar to single-deficient controls, ${ }^{19,41,57}$ while $\mathrm{Atm}^{-/-} \mathrm{Mri}^{-/-}$mice are indistinguishable from $\mathrm{Atm}^{-/-}$littermates ${ }^{23}$ (Figure 2). Taken together, evidence shows that Atm genetically interacts with $K u 70, K u 80$, Dna-pkcs and Xlf, but not with Paxx or Mri. Correspondingly, $X l f$ genetically interacts with Atm, $H 2 a x, M d c l$ and 53bpl.

\section{3 | Genetic interaction between Xlf and Rag}

$X l f$ has also been shown to genetically interact with $\operatorname{Rag} 2 .^{58}$ Mutation in the Rag2 gene results in the truncated protein 'core Rag2', which continues to support DSB formation and DNA repair in developing $\mathrm{B}$ and $\mathrm{T}$ lymphocytes. However, in XLF-deficient cells, this 'core Rag2' activity is lost, and $\mathrm{V}(\mathrm{D}) \mathrm{J}$ recombination does not proceed. This finding suggests a potential role for RAG in both the induction of DSBs and
DNA repair, as the RAG complex supports tethering of DNA ends before ligation ${ }^{58}$ (Figure 2).

\subsection{Neuronal phenotype of NHEJ- deficient mice}

Genomic instability in NHEJ-deficient mice gives rise to increased cell death in the central nervous system (CNS), including the brain, which correlates with embryonic lethality (Figure 1). XRCC4-deficient mice exhibit massive post-mitotic neuronal apoptosis with severe acellularity in the intermediate zone in the neocortex. ${ }^{9,47}$ Similarly, Lig4-deficient mice also exhibit apoptosis of post-mitotic neurons. ${ }^{8}$ While $K u 70^{-/-}$mice are live-born, they possess modestly increased levels of neuronal cell death, which is nevertheless lower than that in $\mathrm{Xrcc}^{-/-}$or $\mathrm{Lig}^{-/-}$mice. ${ }^{11,43,59}$ Inactivation of $\operatorname{Trp} 53$ in $\mathrm{Xrcc}^{-/-}\left(\mathrm{Xrcc}^{-/-} \mathrm{Trp5} 53^{-/-}\right)$and $\mathrm{Lig}^{-/-}$mice $\left(\mathrm{Lig} 4^{-/-} \operatorname{Trp} 53^{-/-}\right.$) significantly reduces neuronal apoptosis in the cortex,${ }^{45,47}$ similar to what is reported in $\mathrm{Lig}^{-/-} \mathrm{Atm}^{-/-}$ mice. ${ }^{46}$ Inactivation of $\mathrm{Ku} 80$ rescues the lethality of $\mathrm{Lig} 4^{-/-}$ mice, ${ }^{43}$ and brains from $\mathrm{Lig} 4^{-/-} \mathrm{Ku} 8 \mathrm{O}^{-/-}$mice are similar to those from $\mathrm{Ku} 80^{-/-}$mice. ${ }^{43}$ XLF-deficient mice show no neuronal defects, ${ }^{34,35}$ although mutations in human $X L F$ are associated with microcephaly. ${ }^{12}$

Single deficiency for Dna-pkcs, ${ }^{9,59}$ Paxx $^{18,19,21,36}$ or $\mathrm{Mri}^{22,23}$ results in mice with no obvious neurological defects. However, mice that are homozygous for Dna-pkcs with point mutation D3922A (kinase dead, Dna-pkcs ${ }^{K D / K D}$ ) possess p53- and Ku-dependent embryonic lethality, as well as increased neuronal apoptosis, with an overall phenotype resembling $\mathrm{XrCC}^{-/-}$and $\mathrm{Lig} 4^{-/-}$mice $^{60}$

Strikingly, combined deficiency for XLF and PAXX $\left(\mathrm{Xlf}^{-/} \mathrm{Paxx}^{-/-}\right),{ }^{18,19,36}$ and XLF and MRI $\left(\mathrm{Xlf}^{-/-} \mathrm{Mri}^{-/-}\right)^{23}$ results in synthetic lethality, which correlates with massive neuronal apoptosis in the neocortex.

Hence, deficiencies in NHEJ often result in neuronal apoptosis, likely due to accumulation of DSBs in post-mitotic neurons.
FIGURE 2 Genetic interactions between NHEJ factors, DDR factors and Rag2 in mice. The phenotypes of mice are indicated. Genetic interactions are marked as $\sqrt{ }$. The lack of interaction is marked as $x$

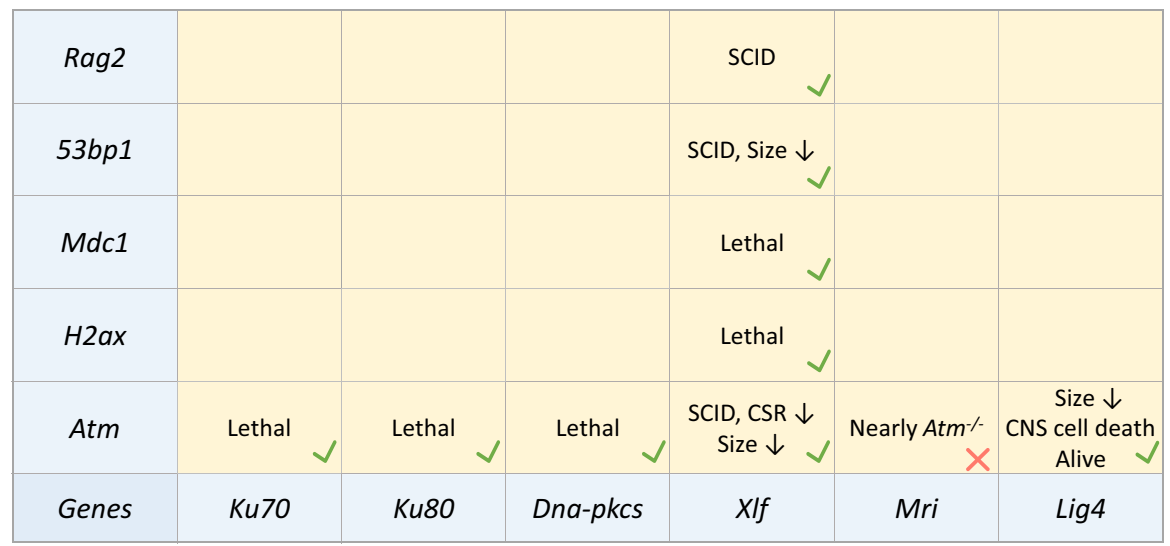

$\checkmark$ Genetic interaction

$\times$ No genetic interaction 
Inactivation of p53 prevents neuronal apoptosis, for example, by allowing A-EJ to repair DSBs in NHEJ-deficient cells.

\section{5 | NHEJ in mouse and human}

Mutations in several NHEJ genes have been identified in humans. ${ }^{61,62}$ For instance, patients with mutations in $X L F$, DNA-PKCS/PRKDC and LIG4 genes display severe clinical features, characterized mainly by SCID, delayed growth and neurological abnormalities. ${ }^{61,62}$ In mice, XLF deficiencies lead to a modest lymphocytopenia and defect in $\mathrm{CSR}^{34,35}$; DNA-PKcs deficiencies lead to a SCID phenotype but no neural complications ${ }^{59}$; and Lig4-deficiencies are embryonic lethal. ${ }^{8}$ In the same manner, ARTEMIS/DCLRE1C-deficient patients are characterized by SCID but not neurological defects ${ }^{62}$; similar to Artemis-deficient mice. ${ }^{17}$ On the other hand, $\mathrm{Xrcc}^{-/-}$mice are embryonic lethal, ${ }^{9}$ unlike XRCC4deficient patients who only display neurological problems. ${ }^{63}$ Mutations in several NHEJ genes have not yet been found in human immunodeficient patients up to the present. These genes include $K u 70, K u 80, P A X X$ and $M R I$. Ku 70 and Ku80 might be essential in human cells, and therefore, mutations in $K U 70$ and $K U 80$ genes might be identified only by analysing embryonic samples. However, mutations in accessory factor genes $P A X X$ and $M R I$ might present without clinical features, based on the knowledge we have obtained from mouse models. ${ }^{18,19,21-23,36}$ In the latter case, XLF might compensate for deficiencies in PAXX and MRI in human cells. Sometimes, dramatic differences in phenotypic presentation between mice and humans lacking the same NHEJ factor can be explained, for example, by minor sequence changes between species, resulting in significant changes in proteinprotein and protein-DNA interactions, and inability for other factors to compensate the protein loss.

\section{6 | Potential reasons for genetic interactions between the NHEJ factors}

There are several types of genetic interaction between the DNA repair factors and several potential explanations for them, although detailed mechanisms have not been elucidated yet.

Why does inactivation of $K u 70^{11}$ or $K u 80^{10}$ result in viable mice, while inactivation of $\mathrm{Lig} 4^{8}$ or $\mathrm{Xrcc}^{9}$ results in embryonic lethality? This cannot simply be due to lack of NHEJ activity, because cells lacking any of these factors are characterized by similar genomic instability. ${ }^{38,40,57}$ The Ku70/ Ku80 complex seems to be toxic for the cells when the NHEJ pathway is blocked due to defects in downstream factors. It is possible that Ku may block access to DSB sites from other DNA repair pathway proteins, preventing DNA ligation and eventually resulting in the accumulation of DSBs, activation of p53 and apoptosis. Interestingly, Ku-deficient cells rely on other DNA repair pathways, such as homologous recombination and alternative end joining. This could also explain why inactivation of $K u 70$ or $K u 80$ rescues embryonic lethality of $\mathrm{Lig}^{-/-}$mice. $^{43,46}$ Similarly, lack of $K u$ rescues embryonic lethality in mice lacking XLF/DNA-PKcs, ${ }^{38,40}$ as well as in mice with an inactivating DNA-PKcs point mutation. ${ }^{60}$ Following the same logic, one can predict that inactivation of $K u 70$ or $K u 80$ would also have the ability to rescue synthetic lethality between Xlf and Paxx, and between Xlf and Mri. We can also predict that inactivation of all NHEJ genes in a mouse would result in a phenotype similar to those of $K u 70^{-/-}$or $K u 80^{-/-}$mice, ${ }^{22}$ and suggest that all NHEJ genes function in a purely Ku-dependent manner.

Synthetic lethality between Xlf and Dna-pkcs, ${ }^{38-40} X l f$ and $\operatorname{Paxx}^{18,19,36,39,42}$ and $X l f$ and $M r i^{23,42}$ results in phenotypes similar to $\mathrm{Lig}^{-/-}$and $\mathrm{XRCC4^{-/- }}$. In all these cases, it is likely that the DNA ligation step is impaired, while Ku70/Ku80 remains functional. There are several potential explanations for the functional redundancy observed between XLF and other factors in NHEJ and DDR. ${ }^{1,38,54,56}$ First, XLF and the second factor could have identical functions, such as having a role in stabilizing the DNA repair complex. A second explanation could be that XLF and the second factor could have purely complementary functions; for example, one protein stimulates DNA ligation while another one is required for DNA end tethering. However, the question of XLF's functionally redundancy with so many other factors $1,18,19,23,36,38-40,42,54$ is still an enigma in the field of DNA repair.

ATM and DNA-PKcs are both protein kinases. Synthetic lethality between Atm and Dna-pkcs ${ }^{46}$ is reasonable to predict because these two proteins can partially compensate for each other's activity when one is inhibited, but no other protein can compensate combined ATM/DNA-PKcs deficiency. ${ }^{52,53,64}$ DNA-PKcs is part of the DNA-PK holoenzyme, which includes Ku70 and Ku80. Both Ku70 and Ku80 are synthetic lethal with Atm, ${ }^{46}$ meaning that ATM is functionally redundant with the Ku70/Ku80/DNA-PKcs complex, and DNA-PKcs will likely be inactive in cells lacking $\mathrm{Ku} 70$ or Ku80.

Deficiency in Atm partially rescues lethality of mice lacking Lig4 ${ }^{46}$ This may be related to the function of ATM, which translates critical accumulation of DSBs to apoptosis via CHK1, CHK2 and p53. Similarly, inactivation of one or both alleles of Trp53 (encoding for p53) rescues embryonic lethality of $\mathrm{Lig}^{-/-}, \mathrm{Xrcc}^{-1-}, \mathrm{Xlf}^{-/-} \mathrm{Dna}$ $\mathrm{pkcs}^{-/-39,40} \mathrm{Xlf}^{-/-} \mathrm{Paxx}^{-/-39,42}$ and $\mathrm{Xlf}^{-/-} \mathrm{Mri}^{-/-42}$ mice. We can infer that the dose-dependent reduction of apoptosis from ATM and p53 deficiency could ensure survival for NHEJ-deficient mice lacking DNA ligation capabilities, albeit these alterations would likely lead to tumorigenesis and cancer. $39,40,42,45-47$ 
Overall, there are complex genetic interactions between the genes of the NHEJ pathway, and between NHEJ and DDR factors. Genetically modified mouse models and murine cell lines have helped to uncover specific functions of DNA repair factors previously hidden due to the functional redundancy. Further studies will uncover additional genetic interactions between the DNA repair factors and pathways. Only a portion of genetic interaction is analysed today, and empty cells represent potential future studies (Figures 1 and 2).

\section{ACKNOWLEDGMENT}

Oksenych group was supported by the grants from Norwegian Cancer Society (\# 182355); Health Authority of Central Norway (\#38811); NTNU enabling technology (2019-2022); and NTNU Stjerneprogrammet (2017-2021).

\section{CONFLICT OF INTEREST}

The authors declare no conflict of interest.

\section{AUTHOR CONTRIBUTIONS}

SCZ and VO wrote most of the manuscript, while all the authors contributed to the initial and revised versions of the manuscript.

\section{ORCID}

Sergio Castañeda-Zegarra (iD https://orcid. org/0000-0002-2808-6788

Marion Fernandez-Berrocal (D) https://orcid. org/0000-0002-5839-9355

Nikki Lyn Esnardo Upfold (iD) https://orcid.

org/0000-0002-6312-5156

Valentyn Oksenych (D) https://orcid.

org/0000-0002-5088-3791

\section{REFERENCES}

1. Kumar V, Alt FW, Oksenych V. Functional overlaps between XLF and the ATM-dependent DNA double strand break response. DNA Repair (Amst). 2014;16:11-22.

2. Alt FW, Zhang Y, Meng FL, Guo C, Schwer B. Mechanisms of programmed DNA lesions and genomic instability in the immune system. Cell. 2013;152(3):417-429.

3. Setiaputra D, Durocher D. Shieldin - the protector of DNA ends. EMBO Rep. 2019;20(5):1-11.

4. Efeyan A, Serrano M. p53: guardian of the genome and policeman of the oncogenes. Cell Cycle. 2007;6(9):1006-1010.

5. Mao Z, Bozzella M, Seluanov A, Gorbunova V. Comparison of nonhomologous end joining and homologous recombination in human cells. DNA Repair (Amst). 2008;7(10):1765-1771.

6. Featherstone C, Jackson SP. DNA double-strand break repair. Curr Biol. 1999;9(20):R759-R761.

7. Graham TG, Walter JC, Loparo JJ. Two-stage synapsis of DNA ends during non-homologous end joining. Mol Cell. 2016;61(6):850-858.
8. Frank KM, Sekiguchi JM, Seidl KJ, et al. Late embryonic lethality and impaired V(D)J recombination in mice lacking DNA ligase IV. Nature. 1998;396(6707):173-177.

9. Gao Y, Sun Y, Frank KM, et al. A critical role for DNA end-joining proteins in both lymphogenesis and neurogenesis. Cell. 1998;95(7):891-902.

10. Nussenzweig A, Chen C, da Costa SV, et al. Requirement for Ku80 in growth and immunoglobulin $\mathrm{V}(\mathrm{D}) \mathrm{J}$ recombination. Nature. 1996;382(6591):551-555.

11. Gu Y, Seidl KJ, Rathbun GA, et al. Growth retardation and leaky SCID phenotype of Ku70-deficient mice. Immunity. 1997;7(5):653-665.

12. Buck D, Malivert L, de Chasseval R, et al. Cernunnos, a novel nonhomologous end-joining factor, is mutated in human immunodeficiency with microcephaly. Cell. 2006;124(2):287-299.

13. Gao Y, Chaudhuri J, Zhu C, Davidson L, Weaver DT, Alt FW. A targeted DNA-PKcs-null mutation reveals DNA-PKindependent functions for $\mathrm{KU}$ in $\mathrm{V}(\mathrm{D}) \mathrm{J}$ recombination. Immunity. 1998;9(3):367-376.

14. Taccioli GE, Amatucci AG, Beamish HJ, et al. Targeted disruption of the catalytic subunit of the DNA-PK gene in mice confers severe combined immunodeficiency and radiosensitivity. Immunity. 1998;9(3):355-366.

15. Kurimasa A, Ouyang $\mathrm{H}$, Dong LJ, et al. Catalytic subunit of DNA-dependent protein kinase: impact on lymphocyte development and tumorigenesis. Proc Natl Acad Sci USA. 1999;96(4):1403-1408.

16. Jhappan C, Morse HC 3rd, Fleischmann RD, Gottesman MM, Merlino G. DNA-PKcs: a T-cell tumour suppressor encoded at the mouse scid locus. Nat Genet. 1997;17(4):483-486.

17. Rooney S, Sekiguchi J, Zhu C, et al. Leaky Scid phenotype associated with defective V(D)J coding end processing in Artemisdeficient mice. Mol Cell. 2002;10(6):1379-1390.

18. Abramowski V, Etienne O, Elsaid R, et al. PAXX and Xlf interplay revealed by impaired CNS development and immunodeficiency of double KO mice. Cell Death Differ. 2018;25(2):444-452.

19. Balmus G, Barros AC, Wijnhoven PW, et al. Synthetic lethality between PAXX and XLF in mammalian development. Genes Dev. 2016;30(19):2152-2157.

20. Xing M, Yang M, Huo W, et al. Interactome analysis identifies a new paralogue of XRCC4 in non-homologous end joining DNA repair pathway. Nat Commun. 2015;6:6233.

21. Gago-Fuentes R, Xing M, Saeterstad S, et al. Normal development of mice lacking PAXX, the paralogue of XRCC4 and XLF. FEBS Open Bio. 2018;8(3):426-434.

22. Castaneda-Zegarra S, Huse C, Røsand $\varnothing$, et al. Generation of a mouse model lacking the non-homologous end-joining factor Mri/ Cyren. Biomolecules. 2019;9(12):798.

23. Hung PJ, Johnson B, Chen BR, et al. Is a DNA damage response adaptor during classical non-homologous end joining. Mol Cell. 2018;71(2):332-342.e338.

24. Zhao B, Watanabe G, Morten MJ, Reid DA, Rothenberg E, Lieber MR. The essential elements for the noncovalent association of two DNA ends during NHEJ synapsis. Nat Commun. 2019;10(1):3588.

25. Pannunzio NR, Li S, Watanabe G, Lieber MR. Non-homologous end joining often uses microhomology: implications for alternative end joining. DNA Repair (Amst). 2014;17:74-80. 
26. Deriano L, Chaumeil J, Coussens M, et al. The RAG2 C terminus suppresses genomic instability and lymphomagenesis. Nature. 2011;471(7336):119-123.

27. Xu Z, Zan H, Pone EJ, Mai T, Casali P. Immunoglobulin classswitch DNA recombination: induction, targeting and beyond. Nat Rev Immunol. 2012;12(7):517-531.

28. Yan CT, Boboila C, Souza EK, et al. IgH class switching and translocations use a robust non-classical end-joining pathway. Nature. 2007;449(7161):478-482.

29. Lieber MR. The mechanism of double-strand DNA break repair by the nonhomologous DNA end-joining pathway. Аnnu Rev Biochem. 2010;79:181-211.

30. Moon AF, Garcia-Diaz M, Batra VK, et al. The X family portrait: structural insights into biological functions of $\mathrm{X}$ family polymerases. DNA Repair (Amst). 2007;6(12):1709-1725.

31. Enervald E, Du L, Visnes T, et al. A regulatory role for the cohesin loader NIPBL in nonhomologous end joining during immunoglobulin class switch recombination. $J$ Exp Med. 2013;210(12):2503-2513.

32. Bjorkman A, Qvist P, Du L, et al. Aberrant recombination and repair during immunoglobulin class switching in BRCA1-deficient human B cells. Proc Natl Acad Sci USA. 2015;112(7):2157-2162.

33. Bosma GC, Custer RP, Bosma MJ. A severe combined immunodeficiency mutation in the mouse. Nature. 1983;301(5900):527-530.

34. Li G, Alt FW, Cheng HL, et al. Lymphocyte-specific compensation for XLF/cernunnos end-joining functions in V(D)J recombination. Mol Cell. 2008;31(5):631-640.

35. Vera G, Rivera-Munoz P, Abramowski V, et al. Cernunnos deficiency reduces thymocyte life span and alters the $\mathrm{T}$ cell repertoire in mice and humans. Mol Cell Biol. 2013;33(4):701-711.

36. Liu X, Shao Z, Jiang W, Lee BJ, Zha S. PAXX promotes KU accumulation at DNA breaks and is essential for end-joining in XLFdeficient mice. Nat Commun. 2017;8:13816.

37. Beck C, Castaneda-Zegarra S, Huse C, Xing M. Oksenych V. mediator of DNA damage checkpoint protein 1 facilitates V(D)J recombination in cells lacking DNA repair factor XLF. Biomolecules. 2019;10(1):60.

38. Oksenych V, Kumar V, Liu X, et al. Functional redundancy between the XLF and DNA-PKes DNA repair factors in V(D)J recombination and nonhomologous DNA end joining. Proc Natl Acad Sci USA. 2013;110(6):2234-2239.

39. Castaneda-Zegarra S, Xing M, Gago-Fuentes R, Saeterstad S, Oksenych V. Synthetic lethality between DNA repair factors Xlf and Paxx is rescued by inactivation of Trp53. DNA Repair (Amst). 2019;73:164-169.

40. Xing M, Bjoras M, Daniel JA, Alt FW, Oksenych V. Synthetic lethality between murine DNA repair factors XLF and DNAPKcs is rescued by inactivation of Ku70. DNA Repair (Amst). 2017;57:133-138.

41. Lescale C, Lenden Hasse H, Blackford AN, et al. Specific roles of XRCC4 paralogs PAXX and XLF during V(D)J recombination. Cell Rep. 2016;16(11):2967-2979.

42. Castañeda-Zegarra S, Zhang Q, Alirezaylavasani A, Oksenych V. Severe immunodeficiency in mice lacking DNA repair factors XLF and Mri. bioRxiv. 2020;1-23. https://doi. org/10.1101/2020.03.04.976829

43. Karanjawala ZE, Adachi N, Irvine RA, et al. The embryonic lethality in DNA ligase IV-deficient mice is rescued by deletion of $\mathrm{Ku}$ : implications for unifying the heterogeneous phenotypes of NHEJ mutants. DNA Repair (Amst). 2002;1(12):1017-1026.
44. Boboila C, Yan C, Wesemann DR, et al. Alternative end-joining catalyzes class switch recombination in the absence of both Ku70 and DNA ligase 4. J Exp Med. 2010;207(2):417-427.

45. Frank KM, Sharpless NE, Gao Y, et al. DNA ligase IV deficiency in mice leads to defective neurogenesis and embryonic lethality via the p53 pathway. Mol Cell. 2000;5(6):993-1002.

46. Sekiguchi J, Ferguson DO, Chen HT, et al. Genetic interactions between ATM and the nonhomologous end-joining factors in genomic stability and development. Proc Natl Acad Sci USA. 2001;98(6):3243-3248.

47. Gao Y, Ferguson DO, Xie W, et al. Interplay of p53 and DNArepair protein XRCC4 in tumorigenesis, genomic stability and development. Nature. 2000;404(6780):897-900.

48. Reiling E, Dollé MET, Youssef SA, et al. The progeroid phenotype of Ku80 deficiency is dominant over DNA-PKCS deficiency. PLoS One. 2014;9(4):e93568.

49. Rooney S, Alt FW, Sekiguchi J, Manis JP. Artemis-independent functions of DNA-dependent protein kinase in Ig heavy chain class switch recombination and development. Proc Natl Acad Sci USA. 2005;102(7):2471-2475.

50. Dewan A, Xing M, Lundbaek MB, et al. Robust DNA repair in PAXX-deficient mammalian cells. FEBS Open Bio. 2018;8(3):442-448.

51. Kumar V, Alt FW, Frock RL. PAXX and XLF DNA repair factors are functionally redundant in joining DNA breaks in a G1-arrested progenitor B-cell line. Proc Natl Acad Sci USA. 2016;113(38):10619-10624.

52. Callen E, Jankovic M, Wong N, et al. Essential role for DNA-PKcs in DNA double-strand break repair and apoptosis in ATM-deficient lymphocytes. Mol Cell. 2009;34(3):285-297.

53. Zha S, Jiang W, Fujiwara Y, et al. Ataxia telangiectasia-mutated protein and DNA-dependent protein kinase have complementary V(D)J recombination functions. Proc Natl Acad Sci USA. 2011;108(5):2028-2033.

54. Zha S, Guo C, Boboila C, et al. ATM damage response and XLF repair factor are functionally redundant in joining DNA breaks. Nature. 2011;469(7329):250-254.

55. Liu X, Jiang W, Dubois RL, Yamamoto K, Wolner Z, Zha S. Overlapping functions between XLF repair protein and 53BP1 DNA damage response factor in end joining and lymphocyte development. Proc Natl Acad Sci USA. 2012;109(10):3903-3908.

56. Oksenych V, Alt FW, Kumar V, et al. Functional redundancy between repair factor XLF and damage response mediator 53BP1 in V(D)J recombination and DNA repair. Proc Natl Acad Sci USA. 2012;109(7):2455-2460.

57. Xing M, Oksenych V. Genetic interaction between DNA repair factors PAXX, XLF, XRCC4 and DNA-PKcs in human cells. FEBS Open Bio. 2019;9(7):1315-1326.

58. Lescale C, Abramowski V, Bedora-Faure M, et al. RAG2 and XLF/ Cernunnos interplay reveals a novel role for the RAG complex in DNA repair. Nat Commun. 2016;7:10529.

59. Gu Y, Sekiguchi J, Gao Y, et al. Defective embryonic neurogenesis in $\mathrm{Ku}$-deficient but not DNA-dependent protein kinase catalytic subunit-deficient mice. Proc Natl Acad Sci USA. 2000;97(6):2668-2673.

60. Jiang W, Crowe JL, Liu X, et al. Differential phosphorylation of DNA-PKcs regulates the interplay between end-processing and end-ligation during nonhomologous end-joining. Mol Cell. 2015;58(1):172-185. 
61. McKinnon PJ, Caldecott KW. DNA strand break repair and human genetic disease. Annu Rev Genomics Hum Genet. 2007;8:37-55.

62. Woodbine L, Gennery AR, Jeggo PA. The clinical impact of deficiency in DNA non-homologous end-joining. DNA Repair (Amst). 2014;16:84-96.

63. Guo C, Nakazawa Y, Woodbine L, et al. XRCC4 deficiency in human subjects causes a marked neurological phenotype but no overt immunodeficiency. J Allergy Clin Immunol. 2015;136(4):1007-1017.

64. Gapud EJ, Dorsett Y, Yin B, et al. Ataxia telangiectasia mutated (Atm) and DNA-PKcs kinases have overlapping activities during chromosomal signal joint formation. Proc Natl Acad Sci USA. 2011;108(5):2022-2027.
How to cite this article: Castañeda-Zegarra $S$, Fernandez-Berrocal M, Tkachov M, Yao R, Upfold NLE, Oksenych V. Genetic interaction between the non-homologous end-joining factors during B and $\mathrm{T}$ lymphocyte development: In vivo mouse models. Scand J Immunol. 2020;92:e12936. https://doi.org/10.1111/ sji.12936 